\title{
Ben Jelloun e o sufismo: \\ o zahir e o bateno
}

Luciana Persice Nogueira

Em três de seus romances, L'enfant de sable, La nuit sacrée e La nuit de l'erreur", Tahar Ben Jelloun faz do narrador um contador de histórias ou, mais precisamente, uma sucessão atordoante de contadores que disputam entre si a voz, a palavra e a autoridade sobre a história. Tendo por palco a praça pública, onde prevalecem a oralidade e a encenação, o contador aglutina ao seu redor a atenção e o olhar de sua halqa (o círculo de audientes). Seu posto permanece como o pivô de onde parte a transmissão da história, mesmo quando o primeiro contador dá lugar ao segundo, e a seqüência de sucessões e de substituições é acionada. As versões da história se acumulam, se encaixam ou se contradizem, enquanto os múltiplos contadores disputam a palavra e a autoridade sobre a história e sobre a halqa. O processo da narração da história, todavia, permanece central na narrativa. No embate entre contadores, observam-se personagens em busca da participação na enunciação, personagens de romance em busca de uma expressão teatral.

A teatralidade é ressaltada pela força cênica do contador, tributário do aedo e do rapsodo gregos, do contador da feira popular medieval européia, e de suas projeções teatrais nas figuras do louco e do bufão. Essa força cênica está impregnada de pathos, e comove audientes e leitor pela sua singularidade trágica; impressiona pela enormidade da tradição que representa, alicerçada tanto no Oriente quanto no Ocidente, no universo aberto e masculino da praça como na clausura doméstica onde as mães e as avós repetem, cercadas por gelosias, os contos de Sherazade.

Os personagens das histórias do contador acrescentam dramaticidade à trama: os secundários e os figurativos são fellinianos, surrealistas, marginais, disformes e grotescos, reforçando o pathos junto à audiência; os principais são trágicos em sua busca da identidade. A tragédia se espraia na caracterização da singularidade, da excepcionalidade e do infortúnio do próprio contador.

* (Ben Jelloun, Tahar. L'enfant de sable. Paris: Seuil, 1985; Ben Jelloun, Tahar. La nuit sacrée. Paris: Seuil, 1987; Ben Jelloun Tahar. La nuit de l'erreur. Paris: Seuil, 1997) 
(Borges, Jorge Luis. Obras completas. V. I, Buenos Aires: Emecé, 1989: 291)
O teatro está presente nos romances de Ben Jelloun através de todo um vocabulário: as histórias serão concebidas ou retratadas, sucessivamente, como tragédia, comédia, drama, encenação, coup de théâtre etc. ou, ainda, através do interesse de personagens de escritores que fazem a sua apologia. De maneira mais contundente, o teatro se manifesta na função de coro do contador, pois ele representa a memória da coletividade, apela para a ordem e tenta - sem muito sucesso-desempenhar papel moralizante. Além de singular, o contador será, por outro lado, coletivo, arcaico e arquetípico.

O teatro se dissemina, igualmente, nas várias máscaras observáveis: nos jogos de claro-escuro do texto, entre aspectos visíveis e invisíveis da trama e dos personagens. De forma geral, ele se reflete na comédia do texto, no debate sobre a questão do riso, implícito na crítica ao fanatismo religioso; na tragédia que envolve os personagens principais; e na paródia que traveste a tragédia de certos personagens secundários.

Um dos aspectos principais dessa teatralidade é a importância das máscaras no texto de Ben Jelloun. Os vários contadores que se sucedem são as várias máscaras do contador emblemático de Ben Jelloun; as identidades do(a) protagonista são as máscaras usadas no processo ininterrupto de metamorfoses que o(a) sustenta; a mistura de gêneros encontrada nos textos poema, conto, romance e teatro - é a máscara barroca da escritura benjellouniana, que desfaz, além de outras, as fronteiras entre gêneros.

Essa máscara barroca, ou neobarroca, deve-se aos hibridismos inerentes à literatura francófona magrebina. Esses hibridismos aproximam-se de uma estética não-unitária, rocambolesca, acidentada, eclética, e que foi definida por Jorge Luis Borges como "estilo que deliberadamente esgota (ou pretende esgotar) suas possibilidades e lida com sua própria caricatura [...] exibe e dilapida seus meios"* - trata-se de uma arte ou maneira de expressão que aponta para a própria máscara. Devido à importância de Borges na obra de Ben Jelloun, os romances em questão serão entendidos como exemplo dessa estética barroca caricatural ou ostensivamente mascarada.

Às vezes denominada "neobarroca” (devido à transferência do termo para o século XX), essa estética caracteriza certas narrativas contemporâneas, por constituirem uma escritura de desregramento e onirismo, onde predomina a inversão: em 
jogos de espelhos, símbolos cifrados, trompe-l'oeil e mises en abyme, temas, personagens e focalização erram entre sombra e luz, aparições e desaparecimentos. A figura trágica do contador principal de L'enfant de sable é um exemplo desse barroco, pois ele aparece e desaparece, sua lucidez vacila, seu lugar é ocupado por outros que, entre usurpações e preenchimentos de lacunas, reorientam sua história a partir de pistas falsas, que ele deixa como rastros atrás de si. Também os personagens de AhmedZahra e de Zina* movem-se em um claro-escuro, entre identidades, aparências, reflexos e projeções. Ou, ainda, os vários contadores de La nuit de l'erreur ${ }^{*}$, que se sucedem de maneira não anunciada, desnorteando o leitor que, por vezes, pode apenas supor quem seja o narrador - ficando, desta vez, o leitor, às escuras, duvidando da própria existência da protagonista.

Do excesso e da diversidade, da abundância rocambolesca, das inversões, inverossimilhanças, lacunas, apagamentos e citações de alfarrábios, surge o efeito de uma unificação barroca máscara unitária assentada sobre miríades, miragem de uma álgebra.

"Máscara”, em grego, é "persona" e informa etimologicamente a palavra "personagem". Não é de se estranhar, portanto, que "máscara" designe, também, o personagem-tipo do teatro: arlequim, colombina etc. O bufão é uma dessas máscaras do teatro, e está presente nos romances através do personagem do contador. O significado primeiro do termo, porém, referese ao objeto usado pelo ator do teatro clássico para expressar emoção ou características básicas, num repertório definido de personagens (rei, mulher, ancião etc).

O uso arcaico da máscara remonta a danças rituais: o dançarino usava uma máscara de animal e, ao fazê-lo, incorporava sua identidade totêmica. A máscara operava uma mutação ou metamorfose no intérprete. Em La nuit de l'erreur, por exemplo, percebe-se um retorno ao uso primitivo, anterior ao próprio teatro: Zina será violentada na noite do Aïd Kebir, noite do sacrifício do carneiro, por homens usando máscaras. Sua violação será comparável a um rito sacrificial (a máscara de Mickey, usada pelos agressores, ou por um deles, porém, retira parte do caráter solene e ritualístico da violação, e aproxima-a do deboche).

Em L'enfant de sable e La nuit sacrée, Ahmed/Zahra será vestido(a) com várias máscaras diferentes, em função das várias versões de sua história, em diferentes identidades. A palavra
" (L'enfant de sable e La nuit sacrée). Daqui em diante, serão usadas nas referên cias as abreviações ES e NS, respectivamente.

"Abreviado, daqui em di ante, como NE. 
- “je n'ai connu de la vie que les masques et les mensonges" (ES: 159).

" "j'ai arraché les racines et les masques" (NS: 83).

- “j'aime bien dire 'J'écris pour ne plus avoir de visa ge!' J'écris pour atteindre un anonymat total où seul le livre parle" (Les yeux baissés. Paris: Seuil, 1991: 232).

" "suis-je un être ou une image [...]? Dis-moi, qui suis.je?" (ES: 50).

- "qui suis-je, et qui est l'autre? [...] Une vieille pièce de monnaie?" (: 55).

- "j'oublie de demander qui je suis" (: 56).

- "après tout je ne sais mê. me pas qui je suis" (: 187).

" "qui êtes-vous? Ne me le dites jamais" (: 100).

" “qui es-tu?" (: 113).

• “qui es-tu?" (: 104).

• "enfin vous voilà!" (: 189). máscara é, aliás, recorrente: "conheci da vida apenas as máscaras e as mentiras"*, e "arranquei as raízes e as máscaras"*, diz, por exemplo, o(a) protagonista, na sua busca de uma identidade definida. Além das duas máscaras de seu "travestimento", o masculino (a máscara Ahmed) e o feminino (a máscara Zahra), há as infinitas máscaras das possibilidades de ser, no inesgotável espectro da individualidade (inclusive a máscara andrógina, colocada no final de La nuit sacrée, quando Zahra deixa o cárcere vestida de homem e maquiada de khôl e batom).

A busca da identidade confunde-se à busca do rosto por detrás da máscara, essa aparência rígida, (im)posta exteriormente; é a busca da essência sob a aparência, do conteúdo sob a forma. Para Ben Jelloun, a identificação desse rosto é uma questão ligada, primeiramente, à própria literatura. Ele dirá, por exemplo, "gosto muito de dizer 'Escrevo para não mais ter um rosto!' Escrevo para atingir um anonimato total onde só o livro fale"** De fato, Ben Jelloun gosta da idéia de não ter um rosto, um nome, ou uma identidade particularizada que o impeça de escrever para um público múltiplo e heterogênio (idéia que se repete, insistentemente, ao longo de sua obra). Para ele, o rosto é metáfora da identidade do escritor, que deve ser disseminada, diluída à medida que escreve um texto literário, obra independente do autor. Nos três romances em questão, é a identidade de Ahmed/Zahra que parece ora diluir-se, ora firmarse, para, em seguida, mutar sob o comando da voz do contador. Em L'enfant de sable, o personagem interroga-se, insistentemente, tragicamente: "sou um ser ou uma imagem? Dizeme, quem sou?"; "quem sou, e quem é o outro? Uma velha moeda?"; " "esqueço de perguntar quem sou"*; "mesmo porque nem sei quem sou”* . As várias faces de Ahmed/Zahra perguntam-se a si-mesmas, mas também perguntam a seus interlocutores ou vêem-se questionadas por eles: "Quem és? Não me diga jamais”; "Quem és?”*. Em La nuit sacrée, Zahra já não mais se coloca essa questão, mas a Assise (sua antagonista) exige uma resposta: "Quem és?"*.

Essa é uma questão edipiana, na base do destino trágico que delimita a trajetória do herói. A definição e o reconhecimento da identidade é um tema clássico, vivenciado por Zahra no final de sua busca: "Até que enfim chegastes!"*, exclama o Cônsul (o interlocutor de Zahra), também ele metamorfoseado (em santo). Em La nuit de l'erreur, Zina diz "não estou certa de 
saber quem sou, realmente", e pergunta "Quem sou? Quem me habita?”* . Na sua confusão entre lenda e mulher, vaticina: "Quem sou? Não sei. Ninguém sabe. Talvez seja apenas um sonho que se apaga”*

A identidade pode ser definida, nesses romances, na relação de alteridade, em função da interação com o outro. Esse outro é, não raro, um duplo. O tema do duplo existe no misticismo muçulmano, que vê o homem como um ícone criado por seu duplo etéreo ou celeste*. Em L'enfant de sable, Ahmed/Zahra terá, pelo menos, três duplos: Fatima (devido à sua excepcionalidade física, ao seu isolamento espacial e à sua sensibilidade), o correspondente anônimo (interlocutor que adivinha e compreende o drama vivido pela personagem) e Fatouma (contadora improvisada cuja biografia se confunde com a sua). É de Fatouma a frase: "na vida, deveríamos poder usar dois rostos... Seria bom ter ao menos um sobressalente... ou então, melhor ainda, não ter rosto algum"*. Ela também é portadora de "duas vidas"*. Ahmed/Zahra vive "dos dois lados do espelho"*, e enxerga certas imagens que vêm do espelho, e outras, do "duplo do espelho"*. Ahmed, no início do romance, é definido como "o duplo da sombra”* A estrutura dupla se revela, também, nas duas Malikas (a governanta da casa e a mulher barbada), e nos dois Bouchaïbs (o contador e o ator viril que interpreta mulheres dominadoras) - a segunda Malika e o segundo Bouchaïb são inseridos no circo, essa outra cena, cena em abyme dentro do romance, onde tudo é interpretado em caricatura.

Em La nuit sacrée, a personagem da Assise incorpora parte dos dilemas vividos por Zahra, revelando uma complementaridade entre ambas. Assise dirá: "não suporto mais ser homem no hamã, mulher em casa, e, às vezes, chego a ser ambos nos dois lugares"*, incorporando a ambigüidade sexual da protagonista. E, em relação à questão edipiana: "saiba que eu sei quem sou. Meu nascimento foi, provavelmente, um erro", aludindo à dúvida existencial de Zahra, e anunciando um parentesco com os personagens vicários de Harrouda (pertencente ao imaginário magrebino, personagem recorrente de Ben Jelloun) aberrações de sexo feminino, ogras que criam o caos ao seu redor, como será Zina. Ou, ainda, estabelecendo com Zahra uma oposição complementar: “Tu és inocente. Eu não.”, e denunciando a ambigüidade pregressa: tem uma visão assustadora com uma mulher travestida de homem* e pressente a androginia
" "je ne suis pas sûre de savoir qui je suis vraiment" (NE: 46).

" "qui suis-je? Qui m'ha bite?" (: 78)

" "qui suis-je? Je ne le sais pas. Personne ne le sait [...] Peut-être ne suis-je qu'un rêve en train de s'éteindre" (: 150).

"(Kohn-Pireaux, Laurence. Étude sur Tahar Ben Jelloun, L'enfant de sable, La nuit sacrée. Paris: Ellipses, 2000: 49)

" "dans la vie on devrait pou voir porter deux visages... Ce serait bien d'en avoir au moins un de rechange... Ou alors, ce qui serait encore mieux, ne pas avoir de visa ge du tout" (ES: 162).

"(: 170) "(: 57)

*(: 167)

" "le double de l'ombre", (: 25).

* “je n'en peux plus d'être un homme au hammam, une femme à la maison, et il m'arrive même d'être les deux à la fois dans les deux lieux" (NS: 73)

" "sache que moi je sais qui je suis. Ma naissance fut probablement une erreur" (: 101).

\footnotetext{
" "tu es innocente. Moi je ne le suis pas" (: 103).

"(: 103)
} 
- "Tu es notre salvatrice, un ange qui est déjà au courant de tout. Tu vas nous mau dire ou nous sauver. Ange exterminateur qui mettra de l'ordre dans cette toile d'araignée" (: 111)

- "il te sera difficile de te soustraire à cet enfer. Enfer ou paradis... à toi de décider" (: 104).
- "Amis, je vous avais dit que cette porte était étroite [...] Cette confession [d'Ahmed] nous éclaire et nous éloigne. Elle rend le personnage de plus en plus étranger" (ES 58).

'(NE: 13) de Zahra ao considerá-la um anjo ("És nossa salvadora, anjo que já está a par de tudo. Vais nos amaldiçoar ou nos salvar. Anjo exterminador que colocará ordem nessa teia de aranha")* - exterminador, como o anjo de Buñuel, que se enreda numa história sem fim. Assise, ainda, antecipa o final do livro: "te será difícil evitares este inferno. Inferno ou paraíso... tu é quem decides"*.

O personagem do Cônsul em La nuit sacrée, será, em certo momento, também, duplo principal do contador Bouchaïb: ao se despedir de Zahra na prisão, dirá:
Tenho que fazer a viagem às trevas, longe de tudo, no deserto, no extremo Sul [...] Teus pensamentos atravessam a noite $[\ldots]$ transcrevê-los [...] algo que escorra como um feixe de luz da Via Láctea, pois trata-se, aqui, da lua cheia, do destino $[\ldots .$.$] És o$ próprio segredo que me possui. Só posso me libertar dele indo até o fim dessa história $[\ldots .$.$] Tua$ história é uma seqüência de portas [...] Tenho que passar por uma porta estreita. Meu papel é de organizá-los e
Je dois faire le voyage des ténèbres, loin de tout, dans le désert, dans l'extrême Sud [...] Vos pensées traversent la nuit [...] Mon rôle est de les organiser et de les transcrire [...] quelque chose qui découle en faisceaux de lumière de la Voie lactée, parce qu'il est question de lune, de destin [...] vous êtes vous-même le secret qui me possède. Je ne peux m'en délivrer qu'en allant jusqu' au bout de cette histoire [...] Votre histoire est une suite de portes [ [...] je suis obligé de passer par une porte étroite.*
E Bouchaïb diz: "Amigos, eu lhes dissera que esta porta era estreita [...]. Essa confissão de Ahmed nos esclarece e distancia. Ela torna o personagem cada vez mais estranho"*. Antes de ser citação de um título de Gide, a "porta estreita” é referência bíblica à opção difícil, à resolução do impasse pela aceitação de um fardo pesado. Tanto Ahmed quanto o Cônsul acabam de fazer uma confissão. Tanto o Cônsul quanto Bouchaïb estão prestes a deixar a cena (para um retorno apoteótico ao final dos romances). Ambos vão para o deserto, para o Sul, para as trevas de uma provação iniciática, iluminada pela lua; ambos estão possuídos pela história, e precisam exorcizá-la.

Em La nuit de l'erreur, Zina é marcada pela duplicidade de seu nome, e afirma ter feito um pacto com uma mulher cuja imagem, diferente da sua, lhe é enviada pelo espelho, dizendo-se "séparée de moi-même comme si j’étais devenue double"; cinde- 
se entre mulher e história de uma mulher. Mais adiante, imaginará ter uma alma gêmea, que denomina Lola e que imagina habitar numa casa em frente à sua*, ou se espelhará em jovens cujas histórias narra em parte (Bahija, que a procura pedindo ajuda*, e as suas quatro hipóstases). Na história de Abid (personagem secundário), Zina tenta fazer dele "irmão no desespero, um duplo, um gêmeo"*.

Todos esses duplos fazem das protagonistas entidades multifacetadas, que não conseguem responder à questão "quem sou?". Ahmed/Zahra é, pelo menos, dois. Zina é mais de cinco. A impossibilidade da resposta única está camuflada na segunda vez que Ahmed/Zahra se pergunta: ("quem sou, e quem é o outro? Uma velha moeda?”* A moeda tem dois lados, cara e coroa, verso e anverso, positivo e negativo, visível e invisível, aparente e oculto. A moeda que cunha esses binômios no tex to é o bateno de que fala o trovador cego, um dos contadores que se revezam na narração da história de Ahmed, e personagem que homenageia Jorge Luis Borges.

A importância de Borges na obra de Ben Jelloun é imensa, e já foi tratada alhures*. Cabe ressaltar, aqui, que a obra do argentino é um dos principais intertextos que se encontram, ora implicitamente, ora não, nos textos do marroquino, desde a concepção da função do escritor, até temas e imagens recorrentes. Os capítulos de L'enfant de sable onde predomina o trovador cego são uma espécie de biografia ficcional de Borges, composta de uma colagem de citações de seus textos.

Todo um inventário dos temas borgianos é desenrolado quando, dirigindo-se aos seus audientes, o trovador fala de uma mulher que o procurara em Buenos Aires: ela tem a voz de um personagem das Mil e uma noites, ela lhe dá uma moeda que ele contrasta com o Zahir, e ela recita do Alcorão; ele lhe fala de seu amor pela escrita árabe, pela caligrafia, pelas miniaturas persas, fala também de labirintos, de "caminhos que se bifurcam”, de bibliotecas, do amigo Stephen Albert, da angústia da passagem do tempo, de Dom Quixote, da Andaluzia, de espelhos, do infinito, de pesadelos, de sonhos e da cegueira...

O trovador estava mesmerizado pela voz da mulher misteriosa, voz das Mile uma noites, e já não prestava atenção ao que era dito. Ela, então, interrompe seu devaneio sobre o fio grave de uma voz feminina, e lhe dá uma moeda antiga, um bateno. Essa é, de acordo com o trovador, uma moeda egípcia de
"(: 55)

" "un frère en désespoir, un double, un jumeau" (: 140).

* "qui suis-je, et qui est l'autre? [...] Une vieille pièce de monnaie?" (ES: 55).

\footnotetext{
"(Nogueira, Luciana Persice. "Borges: intertexto e perso nagem de O Menino de areia de Tahar Ben Jelloun". Universo Hispánico. Lengua. Literatura. Cultura. Vitória: UFES/APEES, 2001: 364 . 367)
} 
"(ES: 175-176)

- "le Zahir est le fond d'un puits à Tétouan, comme il serait, selon Zotenberg une vaine dans le marbre de l'un des mille deux cents pilliers à la mosquée de Cordoue" (: 176).

" (Borges, Jorges Luis. Obras completas. V. I. Op. cit.: 589-595)
- "parce qu'une main étran gère me le donnait. C'était une sorte de mot de passe entre membres d'une mê. me secte" (ES: 176). cinqüenta centavos, não oficial, cunhada em 1851 para circular nas terras de um senhor agrário; em um dos lados está o rosto de um homem, no outro, o de uma mulher; os rostos são semelhantes, à diferença do bigode do homem, e representam gêmeos, filhos do poderoso senhor. O trovador fala, então, do "contrário do bateno": o zahir, moeda de vinte centavos que circulou em Buenos Aires em 1929. E explica que "zahir" significa "aparente e visível”, e "bateno", "interior e oculto". Diz, ainda, que "o Zahir é o fundo de um poço em Tetuan, assim como seria, segundo Zotenberg, um veio no mármore de uma das mil e duzentas pilastras da mesquita de Córdoba"*.

O que é dito sobre o zahir, palavra escrita em maiúscula no texto, cita o conto homônimo de Borges* . A inserção do bateno, em minúscula, cita o seu par no binômio de conceitos zahir/bateno do pensamento islâmico e, sobretudo, sufi (onde Borges busca inspiração). O que é dito sobre o zahir em Ben Jelloun reduz e simplifica a deslumbrante multiplicidade do zahir borgiano (que, além de moeda, fundo de um poço e veio no mármore, é também um tigre, um cego, um astrolábio, e uma bússola nos mais diversos lugares e momentos da história). Essa multiplicidade torna o zahir um objeto ou um ser monstruoso, que ultrapassa a possibilidade concebível do objeto ou do ser, e obsedia e enlouquece todo aquele que o toca.

O trovador diz que o bateno só tinha sentido "porque uma mão estrangeira mo dava. Era uma espécie de senha secreta entre membros de uma mesma seita", - essa "falsa moeda", moeda não oficial, lembra, até certo ponto, a moeda gidiana de Les faux-monnayeurs, cujas produção e circulação podem ser lidas como metáfora do processo escritural. Escritura e moeda associam-se através do personagem do trovador, que diz:
Em toda a minha vida, jamais cessei de opor o poder das palavras $[\ldots]$ à força do mundo real e imaginário, visível e oculto. Preciso confessar que sentia mais prazer a me aventurar no sonho e no invisível do que no que me parecia violento, físico, limitado.
Je n'ai cessé toute ma vie d'opposer le pouvoir des mots $[\ldots .$.$] à la force$ du monde réel et imaginaire, visible et caché. Il faut dire quej'avais plus de plaisir à m'aventurer dans le songe et l'invisible que dans ce qui m’apparaissait violent, physique, limité.*
O trovador opõe as palavras ao mundo (também ele imbuído de duplicidade), a escritura à vida (tema borgiano por excelência). 
O escritor faz a ponte entre esses universos distintos, sobretudo através da construção dos personagens recorrentes do intelectual, do escritor ou do contador - tanto na obra de Borges quanto na de Ben Jelloun.

Zahir é o visível, o aparente, o exotérico; bateno é o invisível, o oculto, o esotérico. Zahir é o símbolo, bateno, o simbolizado. Zahir é a palavra, e bateno, o seu sentido. O binômio zahir/ bateno é apenas um entre vários binômios que marcam a filosofia islâmica. Essa filosofia desenvolve-se em torno do texto corânico e da questão de sua leitura, compreensão e transmissão. Henri Corbin explica que, para essa filosofia,

não há verso corânico que não possua quatro sentidos: o exotérico (zâhir), o esotérico (batin), o limite (hadd) e o projeto divino (mottala). O exotérico é para a recitação oral, o esotérico é para a compreensão interior; o limite são os enunciados que estabelecem o lícito e o ilícito, e o projeto divino é o que Deus se propõe a realizar no homem através de cada versículo.

Essa questão origina-se na Andaluzia do século XI, onde as correntes zahirita e batinita opõem-se em função do sentido da linguagem. Aqueles são literalistas, e estes acreditam que o sentido da palavra só se revela após uma exegese. $\mathrm{O}$ caráter sagrado do texto do Alcorão cria impasses interpretativos de ordem teológica, religiosa, metafísica e científica. Essa discussão ocorre a partir do trabalho de transmissão do Alcorão, mas também no exercício de tradução de textos filosóficos de outras tradições culturais (a grega, por exemplo, com destaque para as traduções de Ibn Rochd da obra de Aristóteles).

De acordo com a crítica Thérèse Michel-Mansour, surgem quatro grupos de pensadores para resolver o impasse interpretativo. Os zahiritas e os batinitas são os mais proeminentes: a escola zahirita, escola do explícito, literalista, entende que não cabe à razão humana compreender os atributos divinos expressos nas palavras (a verdade humana não devendo tocar a verdade divina); e a escola batinita, escola do implícito, não vê limitações ao raciocínio e à consciência humanos**.

Nessa relação com a palavra divina, o próprio nome de Deus torna-se um elemento de revelação: são 99 os seus nomes, cada qual designando um atributo ou princípio divino. Dois deles são, justamente, Ezh-Zhâhir, o Exterior, e El-Bâtin, o Interior*. E Borges, personagem do conto de Borges, só vê uma saída para a loucura que o acomete desde que tocara a moeda:
"(Corbin, Henri. Histoire de la philosophie islamique. Paris: Gallimard, 1986 27-28)

"(Michel-Mansour, Thérèse. La Portée esthétique du signe dans le texte maghré bin. Paris: Publisud, 1994: 31)

" (Schuon, Frithjof. Com prendre I'Islam. Paris: Seuil, 1976: 149) 
(Op. cit.: 595)

- (Clément, Jean-François. "Les trois dimensions de I'Islam", Esprit, Paris, $n^{\circ} 5$. 6, p. 199.206, 1983: 202)

- “pouvoir de l'être invisi. ble" (ES: 90).

• "presque invisible" (: 155) - “j'ai choisi l'ombre et l'in. visible" (: 106).

- "je ne veux pas de nom, je désire l'invisible, ce que tu caches" (: 114).
Zahir, en árabe, quiere decir notorio, visible; en tal sentido, es uno de los noventa y nueve nombres de Dios [ [...] Para perder-se en Dios, los sufíes repiten su próprio nombre o los noventa y nueve nombres divinos hasta que éstos ya nada quieren decir. Yo anhelo recorrer esa senda. Quizá acabe por gastar el Zahir a fuerza de pensarlo y de repensarlo; quizá detrás de la moneda esté Dios. ${ }^{*}$

Borges conhece a prática sufi do dhikr, que consiste em repetir, ao infinito, os 99 nomes de deus. Por detrás da moeda, da monstruosidade prolífica das aparições do Zahir, talvez esteja Deus. Por detrás da multiplicidade, talvez se encontre o Uno. A questão teológica da "unidade na multiplicidade" e da "multiplicidade na unidade" é básica no Islã ${ }^{* 1}$.

A mística muçulmana está imbuída da ambigüidade entre o aparente e o oculto. A ambigüidade de Ahmed/Zahra dramatiza a ambigüidade mística, que tem na figura do andrógino uma importante imagem de completude e totalidade. O texto de Ben Jelloun move-se entre o aparente (zahir) e o oculto (bateno), entre o rosto visível e a individualidade invisível, entre máscaras, simulacros e versões, que são esboços de perfis, sombras de seres imaginados pelos contadores, em constante metamorfose.

Em L'enfant de sable, Ahmed, recluso em seu quarto, cultiva o "poder do ser invisível", do patriarca todo-poderoso "quase invisível", e afirma: "escolhi a sombra e o invisível"*. Ao encontrar a velha decrépita em Zankat Waheb, a "rua de um só" (a rua estreita, onde passa pela provação da "porta estreita", o questionamento sobre a identidade), ela lhe diz: "não quero um nome, desejo o invisível, o que escondes"* O espelho mágico, tema recorrente da literatura árabe, descrito na versão do contador secundário Amar, reflete o "visível e o invisível”*. O espe-

${ }^{1}$ A “unidade com variedade” é uma das normas básicas da composição estética árabe - que supõe um todo unido e universal constituído de elementos particulares, sendo que "o todo tem valor fixo, eterno, e as partes são móveis, temporais, expostas à aniquilação” (Ali Shalaq, La raison dans la théorie esthétique chez les arabes, Beirute, 1985: 85, apud Michel-Mansour, Thérèse. La portée du signe esthétique dans le texte maghrébin. Paris: Publisud, 1994: 34). Essa questão é básica na filosofia e na teologia, de uma maneira geral. Na Bíblia, por exemplo, se lê: "o corpo é um, e no entanto, tem vários membros; mas todos os membros do corpo, não obstante o seu número, formam um só corpo: o mesmo acontece com o Cristo. Pois todos nós fomos batizados em um só Espírito, para formarmos um só corpo, judeus ou gregos, escravos ou homens livres, e todos nós bebemos de um único Espírito” (1 Cor 12, 12-13). As implicações desta e de outras questões de ordem filosófica, por abarcarem tanto o Oriente quanto o Ocidente, escapam ao escopo deste artigo. 
lho devolve a imagem externa; magicamente, revela a imagem interna, o aspecto oculto da identidade (Kohn-Pireau afirma que o tema do espelho na literatura e na filosofia árabes, de caráter neo-platônico, manifesta-se na idéia de que o universo é um conjunto de espelhos nos quais se enxerga a Essência infinita através dos múltiplos reflexos do Ser único. Tem origem, sobretudo, no místico Attar, para quem “o corpo é obscuro como o verso de um espelho, a alma é o lado claro do espelho”, e no hadith que diz: "O fiel é o espelho do fiel"*.

La nuit sacrée, já de início, é uma tradução batinita, pois a surata a que se refere, em árabe, teria por tradução, em francês, "La nuit du destin", constituindo, assim, uma interpretação do escritor, e não uma obediência ao sentido literal. O personagem do Cônsul faz a relação entre visível/invisível e o misticismo sufi: “o que nos traz a nossos poetas místicos, para quem a aparência era a máscara mais perversa da verdade. Tu sabes, pois o viveste em teu corpo, que a claridade é um logro"*. A máscara surge como sinônimo de aparência ilusória, truque ou mentira que dissimula a verdade. E nem a verdade é vista como clara: "a verdade é mais próxima da sombra do que da árvore que projeta essa sombra”; ou ainda, "uma mentira aparente que era, enfim, uma verdade que não se deve nominar”* . A verdade é interior, oculta, não-manifesta, inominável. A máscara é a representação formal de algo que, para o místico, não pode ser representado, pois é inefável. O personagem do pintor Abid qualifica como artística a tarefa de expressar o indizível: "fui fiel aos efeitos da aparência, segui os caminhos do visível, quando deveria ter revelado o que não se expõe"*. A máscara é o corpo masculino de Zahra. Ahmed é uma máscara de Zahra. Enquanto se denomina o personagem Ahmed/Zahra, ressalta-se o seu aspecto dividido entre máscara/individualidade, mentira/verdade, externo/interno, em decorrência da estrutura dicotômica alinhavada por Ben Jelloun em sua trama.

Em La nuit de l'erreur, Dahmane diz: "Ah, os poetas, os contadores de histórias incríveis, os fabuladores [...] os escritores, verdadeiros usurpadores da vida, do aparente e do dissimulado, do visível e do escondido"* Não somente a protagonista é múltipla (tendo, portanto, várias máscaras), mas os próprios escritor e contador estão ligados ao binômio por detrás da máscara, pois seu trabalho, concebido borgianamente, consiste em cruzar as fronteiras entre vida e sonho, real e imaginário.
(: 50$)$

" "cela nous ramène à nos poètes mystiques pour qui l'apparence était le masque le plus pervers de la vérité. Vous savez, puisque vous l'avez vécu dans votre corps, que la clarté est un leurre" (NS: 134).

" "la vérité est plus proche de l'ombre que de l'arbre qui donne cette ombre" (: 133).

" "un mensonge apparent qui était en fait une vérité à ne pas nommer" (: 127).

" "j'ai été fidèle aux reflets de l'apparence, j'ai suivi les chemins du visible alors que ce que j'aurais dû faire, c'était révéler ce qui ne se livrait pas" (NE: 142).

\footnotetext{
" "Ah, les poètes, les conteurs d'histoires incroya. bles, les fabulateurs, les inventeurs [...] les écrivains, véritables cambrioleurs de la vie, de l'apparent et du dissimulé, du visible et du caché" (: 101).
} 
- “je tolérerai l'ambiguitté jusqu'au bout" (ES: 106).

- "je suis sur le chemin de l'anonymat et de la déli. vrance" (: 151).

- (Borges, Jorges Luis. Obras completas. V. I. Op. cit.: 594)

'(Op. cit: 47)

(Marrouchi, Moustapha Ben T. "Breaking up/down/ out of the boundaries: Tahar Ben Jelloun". Em: Research in African Literatures, $\mathrm{s} / \mathrm{I}, \mathrm{n}^{\circ}$ 4, vol. 21, 1990: 80)

" "je ne suis pas amour, mais [...] mirage en décom position" (ES: 69).

“ “je n'étais plus un être de sable et de poussière à l'identité incertaine" (NS: 138).

- "je continuais à consi. dérer mon corps comme un sac de sable [...] Je per. dais le sens de ma présen ce dans le monde. Je me désagrégeais. J'avais l'impression de tomber en ruine et de me reconstituer à l'infini", (: 167).

(Schuon, Frithjof. Com prendre l'Islam. Op. cit.: 175)
A ambigüidade, porém, não se esgota em simples interpolação maniqueísta. Ben Jelloun aponta para a (dis)solução mística em seu texto: Ahmed/Zahra diz "tolerarei a ambigüidade até o fim"*, e "estou no caminho do anonimato e da libertação"*, abrindo mão da identidade, diluindo-a. Zahra assume sua androginia no final de La nuit sacrée, e Zina desdobra-se em várias, na lembrança dos homens do Café Cristal, ou retorna ao mundo lendário, esquecida por Tanger.

Henri Corbin explica que, na filosofia islâmica, a estrutura de todo ser é dupla: há a dimensão humana (zahir) e a dimensão divina (bateno). O sufismo acredita que o encontro das duas dimensões provoca a anulação da bipolaridade pela assimilação da individualidade na divindade - assimilação que constitui a "verdadeira realidade" do Ser. A individualidade é, então, mera máscara ou véu da divindade oculta.

Informado dessa noção, Borges anota: "quien ha visto al Zahir pronto verá la Rosa" e cita: "un verso interpolado en el Asrar Nama (Livro de las cosas que se ignoran) de Attar: el Zahir es la sombra de la Rosa y la rasgadura del Velo"*. O zahir, forma, palavra ou máscara, é instrumento de sua própria anulação.

O nome Zahra, além de significar "flor" ou "rosa", corresponde, segundo Kohn-Pireau, ao verbo "aparecer" ou "manifestar-se", inclusive com a conotação de "revelar-se"*. E Marrouchi acredita na relação etimológica entre "zahir" e "zahra". Ben Jelloun instrumentaliza as repercussões do nome, e, por detrás do binômio Ahmed/Zahra, dissolve a própria polaridade. Ahmed diz: "não sou amor, mas miragem em decomposição"*. Zahra, depois de imaginar-se livre da identidade indefinida, "já não era mais um ser de areia e de pó, de identidade incerta", retorna à sua condição lábil: "continuava a considerar meu corpo como um saco de areia. Eu perdia o sentido de minha presença no mundo. Desagregava-me. Tinha a impressão de despedaçar-me e de reconstituir-me ao infinito"**.

Essa dissolução dinâmica descrita por Zahra parece corresponder ao preceito místico da dissolução da individualidade na divindade, que é também a anulação da identidade. A extinção ( fanâ), nesse contexto, é uma dimensão metafísica na relação entre o real e o ilusório*. É apropriado que a história e a narradora estejam, justamente, na praça Djema el Fna, que significa "o local da extinção", local onde o contador exorciza sua história, a qual oscila entre o real e o ilusório, o passado e o presente, 
o Oriente e o Ocidente, o oral e o escrito, o árabe e o francês... e assimila os opostos, e exaure o antagonismo.

Também Zina é marcada pela dissolução e pela extinção: o velho marabuto lhe diz: "és um ser inacabado", ser - como a criança de areia - lábil e informe. "Saiba que tua beleza é uma máscara. Por detrás esconde-se uma mulher de alma atormentada. Só te restará uma via, a do amor de Deus, da renúncia, da ausência voluntária e do Grande Silêncio, do esquecimento"* Para acabar com a cisão entre mulher e máscara, é preciso renunciar, silenciar, esquecer, tornar-se ausência - extinguir-se, portanto, no amor de Deus.

A dinâmica que supera os binômios funciona como uma dialética que transforma o visível em invisível: a escritura do livro do contador Bouchaïb é "apagada" e "apropriada” pelo clarão da lua cheia*, a pintura do personagem Abid é "engolida” pelo sol*, e o talismã de Zina, escrito pelo marabuto (mais um exorcista), apaga-se à medida em que é lido: “esses signos pesam em tua consciência, por isso escrevo-os, expulso-os de meu espírito com essa tinta que eu mesmo fabrico e que se apaga à medida que se a lê"**

Dinâmica semelhante encontra-se na imagem da história surgida na linha do horizonte, sobre uma tábua flutuante coberta de algas, espumas e palavras, que se seca, se imprime, se apaga e se esquece* . O que era pleno, tornou-se vazio. Como no mecanismo da ampulheta.

A ampulheta é um instrumento de medição do tempo, de vidro, transparente, constituído de dois vasos comunicantes. O compartimento superior, pleno de areia, verte seu conteúdo no inferior, vazio. Com o passar do tempo, pela ação da gravidade, a areia transfere-se de cima para baixo. O vaso que estava pleno esvazia, enquanto o que era vazio, enche. Sua forma lembra o número oito (8), algarismo árabe. Interrompe-se o fluxo da areia de um compartimento a outro tombando-a, e ela adquire a forma do símbolo do infinito $(\infty)$. Mas isso é mera coincidência. De qualquer modo, esses romances falam do tempo infinito ou indefinido, por detrás da máscara da bipolaridade.

Primeiramente, há uma profusão de relógios parados ou quebrados que são mencionados nos três romances. Tanto Ahmed/Zahra quanto Zina têm suas vidas suspensas pela violência que sofrem, e vivem em ritmo de espera, como se fossem atemporais. Fatouma será um personagem "sem idade”*,
" "tu es un être inachevé" (NE: 73)

" "Sache que ta beauté est un masque. Derrière elle est tapie une femme à l'âme trouble [...] II ne te restera qu'une voie, celle de l'amour de Dieu, celle du renoncement, de l'absence volontaire et du grand Silence $[\ldots]$ celle de l'oubli" (: 73)".

${ }^{*}($ ES: 201)

"(NE: 141)

* "ces signes pèsent sur la conscience, c'est pour cela que je les écris, je les ex. pulse de mon esprit avec cette encre que je fabrique moi-même et qui s'efface au fur et à mesure qu'on la lit..." (: 141).

"(: 308)

*(ES: 163) 
· "comme si nous étions, cet homme et moi, enfermés dans une cage de verre, le temps et ses revers" (NS: 183)

- "à présent, mes amis, le temps va aller très vite et nous déposséder. Nous ne sommes plus des specta. teurs, nous sommes nous aussi embarqués dans cette histoire" (: 24).

- "le temps est le rideau qui tout à I'heure tombera sur le spectacle et enveloppera notre personnage sous un linceul" (ES: 126).

- "plus rien ne subsiste de ce que le temps a consigné dans ce livre" (: 201).
Zina alinha-se às ogras lendárias (por exemplo, Harrouda ou Aïcha Kandicha)*. Os contadores são milenares em seu ofício.

Nos dois primeiros romances, a protagonista se verá encerrada em uma "cage de verre" (expressão que se repete, insistentemente), seu quarto isolado na casa, gaiola ou cela vidrada de onde observa o mundo e vê o tempo passar ao seu redor, protegida contra o mundo e contra o tempo (semelhantemente, as crianças do vale do "Jardim Perfumado" excluem-se do mundo, e não envelhecem, como Peter Pan). A imagem do confinamento de vidro se liga ostensivamente à questão do tempo no pesadelo final de Zahra, em La nuit sacrée, no qual a heroína se vê atrelada a um rosto masculino cambiante - ora seu pai, ora seu tio, ora o Cônsul, "como se estivéssemos, este homem e eu, aprisionados em uma cela de vidro, o tempo e seus reveses"*. Esse rosto masculino ao qual está presa é o de seus interlocutores, mas é, também, o de sua identidade em L'enfant de sable. Rostos ou máscaras cambiantes, presos ao tempo e aos seus revezes, ou inversões. Como se inverte a ampulheta, e se faz recomeçar a contagem do tempo. Como se invertem as polaridades que, na passagem da areia, fazem do menino uma menina, e vice-e-versa, no movimento incessante do desejo da identidade. A ampulheta é essa cela vidrada que contém a areia, conta o tempo e funciona em cíclica inversão. Ao final de La nuit sacrée, na forma andrógina escolhida, tomba-se a ampulheta e realiza-se a totalização andrógina - ser completo em si mesmo, pleno de ambigüidades e prolífico em formas, infinito nas possibilidades de ser.

A iminência do tempo é anunciada pelo contador: "agora, amigos, o tempo andará muito rápido e nos despossuirá. Não somos mais espectadores, estamos, também nós, embarcados nessa história"* - o tempo avança sobre a praça e inverte os papéis: de espectadores, os ouvintes da halqa passam a atores co-adjuvantes da história. O tempo tem força dramática, também, mais adiante no texto, quando o contador anuncia: "o tempo é a cortina que, breve, cairá sobre o espetáculo e envolverá nosso personagem sob uma mortalha"*. Bouchaïb dá um tom teatral à história de Ahmed, pois percebe que o tempo se esgota, também para ele (que vai sair, em breve, de cena). Retorna ao palco da praça, no café, e fala sobre o sumiço das letras sobre as folhas do livro: "nada mais resta do que o tempo consignou nesse livro"* Aqui, o tempo é escritor. O texto escrito pelo tem- 
po também será apagado por ele, pois a lua é o primeiro referencial temporal usado pelo homem. História que é vertida de um tempo a outro, como é vertida entre os contadores.

Em La nuit sacrée, Zahra encerra o seu prólogo: "o tempo é o que somos. Ele está em nosso rosto, em nossos silêncios, em nossa espera"* O pai, antes de morrer, diz à filha: "A Noite do Destino te nomeia Zahra, filha da eternidade; és o tempo que permanece no vertente do silêncio"*. Seu renascimento na Noite do Destino sela a contingência da espera, que marca a sua história e a sua trajetória até o final do romance.

Em La nuit de l'erreur, o tempo é diretamente ligado à trama, desde o início: "fui concebida na Noite do Erro, a noite sem amor. Sou o fruto dessa violência feita ao tempo, portadora de um destino que jamais deveria ter sido o meu", diz Zina, definindo o seu nascimento como uma "violência contra o tempo". Além da maldição ligada à coincidência nascimento-morte que ocorre nessa noite, o próprio caráter ritualístico ou sacrificial da violação funciona como um atentado ao tempo, pois é contingência do rito a ruptura da lógica cronológica em proveito do ancestral, do mítico e, portanto, do atemporal. Zina deixa a realidade humana para tornar-se lenda, num mundo circular, de sonhos e seres no limite entre memória e olvido. Zina também vai cobiçar o relógio do tio*, a partir de cuja morte a ambigüidade entre mulher e lenda vai ser desencadeada. Haverá, dentre as histórias encaixadas, a do relojoeiro Rahim, que exorcizava a dor de quem o procurasse, citava filósofos antigos e gostava de "brincar com o tempo": "ele dizia que o presente não existia, ou então, que ele seria a ponta extrema da espada, tão fina quanto invisível’*'. Essa história contada por Jamila explica o nome da Cabana do Enforcado - pois é onde Rahim se suicida durante uma Noite do Erro (e onde Zina será violada, noutra Noite do Erro). E liga o tempo, a filosofia sufi (os "filósofos antigos"), o invisível (o bateno) e a Noite do Erro. $\mathrm{Na}$ história de Salim, o personagem irá à mesma cabana, onde tem a impressão de que o tempo parou*.

No mecanismo da ampulheta, o tempo se desloca com a areia. Esse fio de areia realiza a passagem do pleno ao vazio. Trata-se do mesmo mecanismo de obsessão do contador, receptáculo que é possuído pela história, e que a verte, esvaziando-se dela. É um mecanismo semelhante ao que rege outro binômio importante nos romances: memória e olvido.
" "le temps est ce que nous sommes. II est sur notre visage, dans nos silences, dans notre attente" (NS: 21 ).

* "La Nuit du Destin te nomme Zahra [...] enfant de l'éternité, tu es le temps qui se maintient dans le versant du silence" (: 32).

" "je fus conçue la Nuit de I'Erreur, la nuit sans amour. Je suis le fruit de cette violence faite au temps porteuse d'un destin qui n'aurait jamais dû être le mien" (: 14)

*(: 31 e 81)

* (: 204)

" "il disait que le présent n'existait pas, ou alors, qu'il serait la pointe extrême de l'épée, aussi fine qu'invisible" 
- (Schuon, Frithjof. Com prendre I'Islam. Op. cit.: 145.146)
' (Borges, Jorges Luis. Obras completas. V. I. Op. cit.: 476)
Na mística islâmica, a "lembrança de deus" é o "esquecimento de si”, e inversamente*. Lembrança e esquecimento regem a loucura dos contadores obsediados pela história, e o tormento dos personagens, perseguidos pelo passado, nos três romances.

Despossuídos, marginais e trágicos, os personagens que povoam os romances de Ben Jelloun expõem a ferida que resulta da imigração, do exílio, e/ou da perda da identidade. E, como o imigrante, oscilantes entre lembrança e esquecimento, os corpos feridos de Ahmed/Zahra e de Zina não podem esquecer o passado. Corpo que mascara um ser que se busca, ser que se busca entre trocas de máscaras; corpo que é máscara e metáfora do texto e da escritura.

Esquecer o passado é condição para começar vida nova. Também o migrante deve abrir mão de (parte de) seu passado para integrar-se à terra de adoção. A necessidade de esquecer o passado, para recomeçar ou renascer, reproduz a dialética nascimento-morte na base da maldição da Noite do Erro e do mecanismo da ampulheta.

As máscaras, portanto, são muitas, e travestem, além de personagens, o próprio tempo, um dos temas dos romances, e ligam-se à situação do migrante, que deve portar dentro de si, pelo menos, duas identidades.

Zahir é máscara; bateno, é, entre outros, Borges. O escritor argentino, além de aparecer nos retalhos de citação, é uma presença difusa e invisível que, em suas repetições e circularidades, fala, vertiginosamente, do tempo. O conto "O jardim dos caminhos que se bifurcam” gira em torno de uma parábola sobre o tempo. Esse jardim é um labirinto, que é um livro - um "labirinto de símbolos" e "um invisível labirinto de tempo"*. O calígrafo Ts'ui Pên escrevera: "Dejo a varios porvenires (no a todos) un jardin de senderos que se bifurcan"*, e seu descendente lê, nas entrelinhas, a dimensão temporal dessa bifurcação. Todos os textos escritos existem dentro de um mesmo texto, que se apresenta uno, mas que tem as suas variantes virtuais embutidas, como invisíveis livros sobrepostos ou gigognes. Mas não somente os textos, também os seres bifurcam-se na multiplicidade dos tempos concomitantes, "divergentes, convergentes e paralelos", proporcionando existências concomitantes, distintas entre si. Assim se organizam as versões dos vários personagens, no embaralhamento dos narradores de La nuit de l'erreur. 
L'enfant de sable já conhecera a estrutura bifurcada das numerosas versões. Mas Ahmed/Zahra permanecia um só personagem, mascarado ou vestido de acordo com a fantasia do contador. Zina, todavia, é muitas, todas co-existindo no mesmo texto; também são muitos os narradores que se intrometem não somente na narração, mas na narrativa, fazendo co-existirem focos narrativos distintos, numa profusão barroca, de resultado visual cubista (por acumular registros de diferentes olhares), e que soa como algazarra de vozes narrativas discordantes, dissonantes e inconciliáveis. A máscara atemporal da lenda cria o efeito de unidade e de conciliação final.

Ao final de La nuit sacrée, um efeito de conciliação também é alcançado, quando Zahra diz: "Eu pensava que entre a vida e a morte houvesse somente uma finíssima camada de bruma ou de trevas, que a mentira tecesse seus fios entre a realidade e a aparência, e que o tempo fosse mera ilusão de nossas angústias"** Não apenas a androginia física de Zahra elimina as polaridades, mas o próprio mundo irreal, místico e atemporal onde encerra a sua busca permite a dissolução da vida, da verdade, da realidade, da aparência e do tempo - e o fim das máscaras.

" “je pensais qu'entre la vie et la mort il n'y avait qu'une très mince couche faite de brume ou de ténèbres, que le mensonge tissait ses fils entre la réalité et l'apparence, le temps n'étant qu'une illusion de nos angoisses" (: 189). 
Doutora em Língua Francesa e Literaturas de Língua Francesa (UFRJ). Professora de línguas em Maisons de la Jeunesse et de la Culture em Lyon. Publicações: "Certos elementos do discurso na literatura oriunda das imigrações e a identidade teatral do contador de historias de Tahar Ben Jelloun”, Gragoatá, UFF, Niterói, 2001: 125-140; "Borges: intertexto e personagem de $\mathrm{O}$ menino de areia de Tahar Ben Jelloun”, Universo Hispanico. Lengua, literatura, cultura, UFES/APEES, Vitória, 2001: 364-367.

Palavras-chave sufismo zahir

bateno

máscara tempo ilusão

\section{Resumo}

O texto de Ben Jelloun reveste-se de aparentes ambigüidades: masculino-feminino, mentira-verdade, visível-invisível... Essa estrutura dicotômica funda-se no par zahir-bateno, conceitos da filosofia sufi que são inseridos nas entrelinhas através de Jorge Luis Borges (ora personagem, ora intertexto), e pela menção direta ao misticismo islâmico. Os múltiplos contadores de história e a busca trágica da identidade dos protagonistas revelam o uso obstinado e simbólico da máscara por Ben Jelloun, reforçando a dicotomia, mas revelando o seu caráter ilusório. Outros temas do sufismo podem ser ressaltados: o riso, o dhikr, o duplo, o espelho mágico, a unidade na multiplicidade, a dissolução da individualidade, a extinção - fanâ, e a ilusão do tempo. Esses temas representam a situação e a condição ambíguas do migrante.

\section{Abstract}

Ben Jelloun's text is full of apparent ambiguities: masculinefeminine, lie-truth, visibilityinvisibility... This dichotomic structure is based on the pair zahir-battin, concepts from Sufistic philosophy, inserted in between the lines through Jorge Luis Borges (either as character or as intertext), and through the direct mention of Islamic mysticism. The multiple storytellers and the tragic quest, by the main characters, of their identities, reveal the obstinate and symbolic use of the mask by Ben Jelloun, which reinforces the dichotomy, but also reveals its

\section{Résumé}

Le texte de Ben Jelloun est imbu d'ambiguïtés apparentes: masculinféminin, mensonge-vérité, visibleinvisible... Cette structure dichotomique se fonde sur la paire zahir-batène, qui sont des concepts de la philosophie soufie, insérés dans les interlignes par le biais de Jorge Luis Borges (tantôt personnage, tantôt intertexte), et par la mention directe du mysticisme islamique. Les multiples conteurs et la quête tragique de l'identité par les protagonistes révèlent l'utilisation obstinée et symbolique du masque par Ben Jelloun, en renforçant la dichotomie, mais tout en révélant son 
illusory nature. Other Sufi themes can be stressed: laughter, the dhikr, the double, the magic mirror, unity in multiplicity, the dissolution of individuality, the extinction - fan $\hat{a}$, and the illusion of time. These themes represent the ambiguous situation and condition of the migrant. caractère illusoire. D'autres thèmes du soufisme peuvent être mis en relief: le rire, le dhikr, le double, le miroir magique, l'unité dans la multiplicité, la dissolution de l'individualité, l'extinction-fanâ, et l'illusion du temps. Ces thèmes représentent la situation et la condition ambiguës du migrant.
Recebido em 10/08/2002 Aprovado em 12/07/2003 